\title{
Correlações técnicas e ocupacionais da radiologia intervencionista
}

\section{Occupational and technichal correlations of interventional radiology}

Edvaldo de Souza ${ }^{1}$, José Paravidino de Macedo Soares ${ }^{2}$

\begin{abstract}
Resumo
A radiologia diagnóstica é a área da física médica relacionada ao uso de raios X para a obtenção de informações anatômicas e funcionais do corpo humano. As técnicas associadas a essa área utilizam tubos de raios $\mathrm{X}$ como fontes de radiação, filmes para o registro das informações, sistemas de monitoração por televisão e equipamentos que digitalizam as imagens utilizando computadores. Os equipamentos de fluoroscopia são considerados fontes artificiais de radiação ionizante e são utilizados para a realização de exames e procedimentos nas doenças vasculares. O objetivo deste estudo foi analisar criticamente os métodos de proteção em relação à radiação emitida pela fluoroscopia utilizados pelos profissionais que lidam com a radiologia intervencionista no ambiente hospitalar. Foi realizada uma análise crítica das atitudes de proteção tomadas pelos profissionais engajados nos procedimentos da radiologia intervencionista a partir da revisão bibliográfica realizada em livros-textos e em revistas periódicas indexadas no MEDLINE, nas línguas portuguesa, inglesa, francesa e espanhola, no período de 1966 a 2005, conforme os princípios e as normas de segurança de proteção radiológica norteadas pela Portaria 453/98 do Ministério da Saúde e a norma da Comissão Nacional de Energia Nuclear NN-3.01 do Ministério da Ciência e Tecnologia.
\end{abstract}

Palavras-chave: Radiação ionizante, radiologia intervencionista, fluoroscopia, proteção radiológica, raios X.

\section{Introdução}

A radiologia intervencionista pode ser definida como a área de atuação médica que emprega o uso das radiações ionizantes, tais como os raios $\mathrm{X}$ e a fluoroscopia, para a obtenção de informações capazes de permitir procedimentos diagnósticos e terapêuticos e vem sendo cada

\begin{abstract}
Diagnostic radiology is a field of physical medicine that uses $\mathrm{X}$ rays to obtain functional and anatomical information on the human body. The techniques associated to this area use $\mathrm{X}$ ray tubes as radiation sources, films to record information, and monitoring systems using television and computers for the digitalization of images. Fluoroscopic equipment is considered as artificial springs of ionizing radiation and is used in diagnostic exams and procedures of vascular illnesses. The objective of this study was to critically analyze the protection methods regarding the radiation emitted by fluoroscopy used by professionals dealing with interventional radiology in a hospital environment. An evaluation of protection methods adopted by professionals directly involved in procedures of interventional radiology was performed based on extensive literature review of textbooks and medical journals indexed on MEDLINE in Portuguese, English, French, and Spanish from 1966 to 2005. It is in accordance with the radiological protection security norms and regulations guided by Edict 453/98 of the Brazilian Department of Health and the National Commission of Nuclear Energy NN-3.01 of the Brazilian Department of Science and Technology.
\end{abstract}

Keywords: Radiation, ionizing, interventional radiology, fluoroscopy, radiation protection, $\mathrm{X}$ rays.

vez mais utilizada, já que metade da população mundial realiza um exame radiológico por ano ${ }^{1-6}$. Em virtude dos benefícios gerados pelo uso dos equipamentos de fluoroscopia nos diversos tipos de procedimentos relacionados às doenças vasculares, cuja principal característica é permitir a visualização em tempo real, guiando

1. Mestre, Cirurgia Vascular, Universidade Federal de São Paulo (UNIFESP), São Paulo, SP. Especialista, Angiologia e Cirurgia Vascular, SBACV e Associação Médica Brasileira (AMB). Sócio efetivo, SBACV-SP. Associado titular, Associação Nacional de Medicina do Trabalho (ANAMT).

2. Mestre. Professor e coordenador, Curso de Especialização de Medicina do Trabalho, Universidade Federal Fluminense (UFF), Niterói, RJ.

Trabalho desenvolvido no Curso de Pós-Graduação Lato Sensu: Especialização em Medicina do Trabalho, da Universidade Federal Fluminense, Niterói, RJ, como requisito parcial para a obtenção do certificado de Especialização em Medicina do Trabalho, no ano de 2006.

Não foram declarados conflitos de interesse associados à publicação deste artigo.

Artigo submetido em 19.08.07, aceito em 26.08.08.

J Vasc Bras. 2008;7(4):341-350.

Copyright@ 2008 by Sociedade Brasileira de Angiologia e de Cirurgia Vascular 
as manobras diagnósticas e/ou terapêuticas que estão sendo realizadas, seu uso freqüente é capaz de produzir efeitos nocivos à saúde dos profissionais envolvidos, já que os mesmos são considerados fontes artificiais de radiação ionizante ${ }^{2,5}$. Faz-se necessário, portanto, que o profissional deva se expor o menor tempo possível à radiação emitida pelo aparelho ${ }^{4-12}$.

Sabe-se que a falta de vestimentas de proteção individual e a ausência de um controle periódico são alguns dos exemplos que demonstram a desatenção dada às radiações ionizantes no Brasil ${ }^{13}$, o que condiz com a necessidade de programas específicos de qualificação dos profissionais envolvidos nessas atividades, a fim, inclusive, de se garantir uma boa qualidade técnica do exa$\mathrm{me}^{8,12,14,15}$. O sistema de proteção radiológica deve se empenhar em manter a exposição ocupacional abaixo do limiar recomendado, evitando-se, assim, os efeitos estocásticos, já que os efeitos biológicos produzidos pela radiação são cumulativos. Para isso, é imperioso o uso do equipamento de proteção individual (EPI) adequado ${ }^{6}$.

Este estudo tem como objetivo analisar criticamente os métodos de proteção em relação à radiação emitida pela fluoroscopia utilizados pelos profissionais que lidam com a radiologia intervencionista no ambiente hospitalar, por meio de uma análise crítica das atitudes de proteção tomadas pelos profissionais engajados nos procedimentos da radiologia intervencionista, a partir de revisão bibliográfica realizada em livros-textos e em revistas periódicas indexadas no MEDLINE, nas línguas portuguesa, inglesa, francesa e espanhola, no período de 1966 a 2005, conforme os princípios e as normas de segurança de proteção norteadas pela Portaria 453/98 do Ministério da Saúde (MS) e a norma da Comissão Nacional de Energia Nuclear (CNEN) NN-3.01 do Ministério da Ciência e Tecnologia.

\section{Sistema de radioproteção}

A proteção radiológica tem por objetivo proteger adequadamente os profissionais sem limitar desnecessariamente as práticas benéficas que utilizam com a radiação ionizante. O sistema de radioproteção é fundamentado em princípios básicos, que visam garantir que a dose equivalente recebida por alguma pessoa seja tão baixa quanto razoavelmente exeqüível (princípio as low as readily achievable, ALARA); que nenhum emprego de radiação seja injustificado em relação a seus benefícios; e que a dose equivalente não exceda os limites anuais de dose para os profissionais. Dessa forma, em um programa de monitoração ocupacional, os pontos de maior preocupação com os indivíduos expostos são: a jornada de trabalho, a formação dos funcionários, o treinamento periódico, a dosimetria pessoal e os exames médicos de rotina ${ }^{2,3,5,16,17}$. Deve haver, ainda, treinamento anual e educação continuada permanente sobre proteção radiológica de todos os profissionais envolvidos com as atividades, pois a responsabilidade em se cumprir as regulamentações se aplicam a $\operatorname{todos}^{17,18}$. Conforme regulamentações da Associação Brasileira de Normas Técnicas (ABNT), todo profissional que trabalha com radiodiagnóstico deve usar um dosímetro sempre e somente quando estiver na área de risco e ainda submetê-lo mensalmente para a leitura dos dados nele contido, a fim de monitorizar a radiação individual acumulada, fornecendo, assim, informações acerca da exposição à radiação ionizante ${ }^{3,15,19}$. Atualmente, a maioria dos estabelecimentos fornece monitores ou dosímetros individuais para os profissionais, mas, por outro lado, verifica-se que em alguns casos os profissionais desconhecem a importância do uso dos monitores individuais e os limites de doses mensais recomendados. Prova disso é a constatação de não ser incomum o armazenamento de forma coletiva e não individual de seus dosímetros junto ao monitor padrão ao final do expediente, tampouco a utilização correta dos mesmos, conforme se recomenda ${ }^{13,15}$.

Segundo Soares ${ }^{2}$ e o que consta na norma CNEN$\mathrm{NN}-3.01^{20}$, as principais grandezas recomendadas para uso em proteção radiológica segundo a International Commission on Radiological Protection (ICRP), com objetivos de limitação da exposição do homem à radiação ionizante, são: a) dose absorvida no órgão, que serve para quantificar a energia depositada em um órgão ou tecido. Essa grandeza dosimétrica é expressa por $\mathrm{D}=$ $\mathrm{d} \varepsilon / \mathrm{d}_{\mathrm{m}}$, em que de é a energia média depositada pela radiação em um volume elementar de matéria de massa $\mathrm{d}_{\mathrm{m}}$. A unidade de dose absorvida no sistema internacional (SI) é o joule por quilograma (J/kg), denominada 
Gray (Gy); b) dose equivalente, que, além de quantificar a energia depositada em um órgão ou tecido, fornece informações acerca do dano biológico causado por cada tipo de radiação, que, nesse caso, se refere aos raios $X$. Quantidades iguais de dose absorvida em um órgão ou tecido, devido aos diferentes tipos de radiações, causarão efeitos biológicos diferentes. A unidade no SI é o $\mathrm{J} / \mathrm{kg}$, denominada Sievert (Sv); c) dose efetiva, definida como sendo o somatório do produto das doses equivalentes por um fator de peso $\left(\mathrm{W}_{\mathrm{T}}\right)$ para tecidos ou órgãos, usada para, além de se considerar o tipo de radiação que deposita energia no corpo humano, considerar também a parcela de contribuição de cada órgão irradiado no detrimento à saúde. Os valores de dose efetiva estão associados à radiossensibilidade do órgão ou do tecido irradiado. A unidade no SI é o J/kg, também denominada $\mathrm{Sv}$, e sofre variações conforme o peso da maioria dos órgãos ou tecidos (Tabela 1). A Portaria 453/98 do MS, que retrata a ICRP 60 (publicação $n^{\circ}$ 60, de 1990), define que a dose efetiva média anual não deve exceder a 20 miliSievert (mSv) em qualquer período de 5 anos consecutivos; a $50 \mathrm{mSv}$ em nenhum ano; ou a $500 \mathrm{mSv}$ para extremidades e $150 \mathrm{mSv}$ para o cristalino (Tabela $2)^{15,20}$. Caso o profissional venha a trabalhar em outros serviços, os responsáveis de cada serviço devem providenciar para que a soma das exposições ocupacionais desse profissional não exceda os limites apontados na Portaria 453/98 do MS ${ }^{15}$. Levando em consideração o princípio ALARA, faz-se necessário o conhecimento das doses equivalentes das equipes da unidade de hemodinâmica. Para o bom posicionamento dos componentes das equipes na sala de exames, a otimização do sistema de proteção radiológica e a minimização das doses de radiação justificariam a implantação de uma sistematização do funcionamento das unidades que têm aparelhos de fluoroscopia operados por essas equipes, o que resultou no desenvolvimento e implantação de um sistema de segurança para controle das fontes de radiação e proteção radiológica dos profissionais expostos na Universidade Federal do Rio Grande do Sul (UFRGS) a partir do ano $2001^{12,15,16}$. As blindagens são utilizadas para deter a propagação das radiações, evitando, assim, exposições desnecessárias de pessoas envolvidas com equipamentos que emitem radiação ionizante. Sua eficiência é determinada pela capacidade de penetração dos raios $\mathrm{X}$, assim como pela natureza e espessura do material de blindagem ${ }^{2,10,21}$. Os profissionais, na sala de exame, devem posicionar-se de tal forma que nenhuma parte do corpo, incluindo extremidades, seja atingida pelo feixe primário sem que esteja protegida por $0,5 \mathrm{~mm}$ equivalentes de chumbo e também se proteger da radiação espalhada por vestimenta ou barreiras protetoras com atenuação não inferior a $0,25 \mathrm{~mm}$ equivalentes de chumbo $^{15,17}$. Os objetivos da radioproteção são a prevenção ou diminuição dos efeitos somáticos das radiações e a redução da deterioração genética das populações. A dose acumulada ao longo dos anos causa, gradativamente, mais e mais modificações dos genes, ainda que doses intermitentes recebidas durante o período sejam pequenas. A exposição à radiação ionizante sempre causa danos às células. Não existe um valor de dose de radiação que seja considerado seguro. Alguns dos danos somáticos causados por exposição podem ser reversíveis, porém os danos genéticos são cumulativos e irreversíveis. Por essa razão, deve-se procurar reduzir ao máximo a exposição radiológica do profissional e da população ${ }^{2}$.

Oliveira $^{5}$, com relação ao registro de dose de radiação, informa que a ICRP definiu o "nível de registro" como sendo o valor a partir do qual deve ser realizado o registro numérico do valor medido da grandeza de interesse. Valores inferiores ao nível de registro são de pouca importância para a proteção radiológica, sendo considerados como zero. No Brasil, segundo a norma CNENNN-3.01 e a Portaria 453/98 do MS, o valor considerado para nível de registro deve ser igual ou superior a $0,20 \mathrm{mSv}^{15,20}$.

Oliveira ${ }^{5}$ classifica o profissional como em "nível de investigação" quando sua dose mensal de radiação obtida do monitor está entre 1,2 mSv e 4,0 mSv. Nesses casos, são realizadas investigações locais para verificar o ocorrido, sendo necessária a justificativa de procedimentos do profissional durante o mês de referência.

Segundo Oliveira ${ }^{5}$, a classificação de "ultrapassado no mês" indica que as doses de radiação atingiram o limite de 4,0 mSv e, dessa forma, tal ocorrência deve ser comunicada às autoridades competentes, podendo a instituição ser vistoriada por órgão de fiscalização, e o funcionário, dependendo da gravidade da exposição, pode 
Tabela 1 - Fatores de peso $\left(\mathrm{W}_{\mathrm{T}}\right)$ para órgãos ou tecidos (modificada de Soares ${ }^{2}$ )

Tecido/órgão humano

Fatores de peso $\mathrm{W}_{\mathrm{T}}$ - ICRP 60

Gônadas

0,20

Mama

0,05

Medula óssea (vermelha)

0,12

Pulmão

0,12

Superfície óssea

0,01

Tireóide

0,05

Cólon

0,12

Estômago

0,12

Fígado

0,05

Bexiga

0,05

Esôfago

0,05

Pele

0,01

Outros órgãos*

0,05

Irradiação do corpo inteiro

1

ICRP = International Commission on Radiological Protection.

* Como outros órgãos consideram-se apenas cinco órgãos ou tecidos: cérebro, intestino grosso superior, intestino delgado, rins, útero, pâncreas, vesicula, timo, adrenais e músculo, que recebem as doses equivalentes mais elevadas. Para cada um desses órgãos, relaciona-se um fator WT igual a 0,006 .

Tabela 2 - Limites de doses anuais* (modificada de Soares $^{2}$ )

Grandeza/órgão Indivíduo ocupacionalmente exposto

Dose efetiva

Corpo inteiro

$20 \mathrm{mSv}$

Dose equivalente

Cristalino

$150 \mathrm{mSv}$

Pele

$500 \mathrm{mSv}$

Mãos e pés

$500 \mathrm{mSv}$

$\mathrm{mSv}=$ miliSievert

* Ano calendário, período de janeiro a dezembro de cada ano. 
vir a ser afastado de qualquer atividade que utilize radiações ionizantes.

O termo dose desconhecida significa que por algum motivo a dose mensal de radiação não foi avaliada e, assim, deve-se atribuir ao período em que a dose não foi determinada um valor médio, que é obtido com a média dos valores medidos no ano em questão ${ }^{5}$.

Os profissionais devem seguir um padrão de proteção radiológica que tem como princípios fundamentais os seguintes pontos: a) justificação - qualquer atividade envolvendo a radiação ou exposição deve ser justificada em relação a alternativas disponíveis e também produzir um benefício significativo para a sociedade. $\mathrm{O}$ beneficio tem de ser tal que compense o procedimento ou exame radiológico; b) otimização - sempre utilizar a menor dose possível de radiação; c) limitação da dose as doses individuais de profissionais e de indivíduos do público não devem ultrapassar os limites primários de doses anuais que constam em normas da CNEN, as quais retratam normas estabelecidas por órgãos internacionais de proteção radiológica; d) prevenção - todo esforço deve ser direcionado para estabelecer medidas rígidas para a prevenção de acidentes ${ }^{2,6}$.

A Portaria 518/2003 do Ministério do Trabalho e Emprego (MTE), publicada no Diário Oficial da União de 07/04/2003, adota como atividades perigosas, entre outras, as atividades de operação com aparelhos de raios $\mathrm{X}$ que constam no quadro de atividades e áreas de riscos apresentado na norma regulamentadora (NR) 16. Essa Portaria destaca que qualquer exposição do trabalhador às radiações ionizantes é potencialmente prejudicial à sua saúde, considerando que mesmo as novas tecnologias introduzidas nos aparelhos de radiologia e nos equipamentos de proteção individual (EPI) não permitem a eliminação desse risco. Essas atividades também fazem parte da relação de atividades e operações perigosas aprovada pela CNEN. O trabalho perigoso relativo à exposição do trabalhador à radiação ionizante assegura ao empregado o adicional de periculosidade de $30 \%$ sobre o salário básico, conforme trata o parágrafo $1^{\circ}$ do artigo 193 da Consolidação das Leis Trabalhistas (CLT) ${ }^{22-24}$.

\section{Tipos de monitores de dose de radiação}

Existem diversos tipos de monitores de dose de radiação ou dosímetros, podendo se destacar o monitor fotográfico (filme), o termoluminescente (TLD), que é o mais utilizado nos serviços de radiologia, e o eletrônico. Os dosímetros de extremidade (pulseira, anel) são geralmente indicados para os profissionais que lidam com equipamentos de fluoroscopia ${ }^{6,25}$. No entanto, cada tipo de monitor possui vantagens e desvantagens, que devem ser "pesadas" em relação aos fatores diversos de cada serviço de radiologia ${ }^{4,26}$.

O dosímetro TLD é um dispositivo composto de cristais com propriedades termoluminescentes - quando aquecido emite luz - utilizado para medir doses de radiações ionizantes, como as geradas por aparelhos de raios $\mathrm{X}$ ou fontes radioativas, cuja intensidade é proporcional à dose da radiação incidente. Os monitores TLD devem ser posicionados sobre o avental de chumbo na altura do tórax, e o serviço de proteção radiológica deverá informar à empresa responsável sobre a monitoração individual, cabendo a ela calcular a dose efetiva recebida ${ }^{6,27}$.

O dosímetro é de uso individual e deve ser utilizado durante todo o período de trabalho do profissional. No período em que não estiver sendo utilizado, ele deve ser guardado junto com os outros dosímetros dos profissionais da instituição e do dosímetro padrão. O dosímetro padrão é utilizado como referência no sistema de leitura, ou seja, as doses indicadas no laudo de doses mensal são calculadas medindo-se a dose do dosímetro de cada usuário e subtraindo-se o valor da dose acumulada no dosímetro padrão ${ }^{27,28}$.

Além dos monitores individuais, as áreas sob controle de proteção radiológica deverão manter os monitores de área para controle regular de radiação do ambiente. As áreas consideradas livres de radiação são aquelas em que a radiação não ultrapassa $1 \mathrm{mSv} / \mathrm{mês}$. As áreas restritas são de acessos controlados, por apresentar níveis de radiação maiores que $1 \mathrm{mSv} / \mathrm{mês}$, e são subdivididas em: a) área supervisionada, para os níveis de radiação entre $1 \mathrm{mSv} /$ mês e $3 \mathrm{mSv} / \mathrm{mês}$; b) área controlada, se os níveis de radiação forem superiores a 3 $\mathrm{mSv} / \mathrm{mês}^{6}$. 
A Portaria 453/98 do MS especifica, para fins de planejamento de barreiras físicas e verificação de adequação dos níveis de radiação em levantamentos radiométricos, os seguintes níveis de equivalentes de dose ambiente adotados para restrição de dose: $5 \mathrm{mSv} / \mathrm{ano}$ para áreas controladas e $0,5 \mathrm{mSv} / \mathrm{ano}$ para as áreas livres ${ }^{15}$.

\section{Equipamento de proteção individual}

Segundo a NR 6, EPI é todo dispositivo que o trabalhador deve usar para protegê-lo dos riscos suscetíveis de ameaçar a sua segurança e sua saúde. Devem, ainda, ter Certificado de Aprovação (CA) concedido pelo MTE ao qual cabe fiscalizar a qualidade do $\mathrm{EPI}^{29,30}$.

Os EPI são os seguintes: a) aventais plumbíferos com $0,5 \mathrm{~mm}$ equivalentes de chumbo; b) protetor de tireóides plumbífero com $0,5 \mathrm{~mm}$ equivalentes de chumbo; c) luvas plumbíferas com dedos de $0,25 \mathrm{~mm}$ equivalentes de chumbo; d) óculos com vidro plumbífero anterior e lateral de $0,5 \mathrm{~mm}$ equivalentes de chumbo.

Os profissionais que não estiverem próximos ao feixe primário devem se proteger da radiação espalhada com equipamentos protetores com atenuação não inferior a $0,25 \mathrm{~mm}$ equivalentes de chumbo ${ }^{15}$.

A radiação secundária ou espalhada é a fonte principal de irradiação dos profissionais. Aventais de chumbo com $0,5 \mathrm{~mm}$ de espessura podem interceptar até $98 \%$ da radiação secundária e com $0,25 \mathrm{~mm}$ detêm até $96 \%$, protegendo as gônadas e cerca de $80 \%$ da medula óssea ativa. Os protetores de tireóide podem reduzir a exposição da glândula em até 10 vezes ${ }^{31}$.

As luvas cirúrgicas plumbíferas, que são comercializadas, possuem um fator de atenuação contra a radiação que varia de 5 a $20 \%$, dependendo do modelo. Porém, mesmo com as luvas protetoras, o médico deve evitar a exposição de sua mão no campo de irradiação ou sob o intensificador de imagem, pois esse procedimento raramente se constitui em uma necessidade médica. Por diminuir a sensação tátil, poder prolongar o procedimento e também causar maior radiação na mão, visto que essas luvas não dão proteção eficaz, o seu uso é pouco difundido ${ }^{31}$.
Além dos equipamentos listados acima, todo equipamento de fluoroscopia deve possuir cortina ou saiote plumbífero, inferior e lateral, assim como biombos ou anteparos móveis de chumbo, com espessura não inferior a $0,5 \mathrm{~mm}$ equivalentes de chumbo para proteção do operador contra a radiação espalhada pelo paciente. Estudos feitos com procedimentos de cateterismo cardíaco relatam que há uma redução eficiente das doses dos médicos em $50 \%$ quando o anteparo de chumbo lateral está bem localizado entre o médico e o paciente durante os exames. Os biombos móveis, quando bem utilizados, reduzem a exposição dos profissionais que operam o aparelho de hemodinâmica em até $85 \%$ da radiação; quando os biombos não são utilizados, a posição grosseira de dois passos de distância da mesa de exame pode reduzir pela metade a radiação secundária ${ }^{6,14,15,17,18,31}$.

As vestimentas plumbíferas em nenhum momento devem ser dobradas e quando não estiverem em uso devem ser mantidas em superfície horizontal ou em suporte apropriado, pois, ao se dobrar, o revestimento de chumbo pode fraturar e violar o sistema de radioproteção ${ }^{6,15}$.

Balter ${ }^{31}$ adverte que raramente uma falha de proteção das vestimentas plumbíferas pode ser detectada visualmente e que as mesmas devem passar pela fluoroscopia anualmente para verificação de sua integridade.

Os equipamentos de proteção devem estar disponíveis gratuitamente e em boas condições de uso nos serviços de radiodiagnóstico, e os profissionais da equipe de saúde devem estar aptos a utilizar e conservar de forma adequada esses equipamentos ${ }^{17,29,30}$.

Segundo Balter ${ }^{31}$, ao não se utilizar os EPI plumbíferos durante os exames de cateterismo vascular, o profissional aumenta a dose de exposição por um fator de 10 ou mais.

\section{Princípios físicos da produção de raios $\mathbf{X}$}

Os raios X são fótons que se originam na eletrosfera do átomo e, como são radiações eletromagnéticas, não têm carga nem massa (diferente das radiações nucleares alfa e beta, que são eletrocarregadas e têm números de massa próprios) e são constituídos de pura energia, como a luz que enxergamos ${ }^{1,2}$. 
A produção de radiação se dá no tubo de raios X, ao ser aplicada uma corrente elétrica de alta voltagem, que ao aquecer um filamento metálico chamado catodo provoca o deslocamento acelerado de elétrons, que irão se chocar contra um anteparo de metal chamado anodo após passar pelo vácuo presente no tubo de raios X. A energia dos elétrons e, conseqüentemente, do feixe de raios $\mathrm{X}$ gerado no anodo está diretamente relacionada com a tensão (quilovolt, $\mathrm{kV}$ ) imposta entre o catodo e o anodo e a corrente elétrica (miliampère, $\mathrm{mA}$ ) aplicada ao aparelho ${ }^{2,32}$.

Os raios $\mathrm{X}$ possuem propriedades físicas muito importantes, tais como: a) enegrecem filme fotográfico; b) produzem radiação secundária ou espalhada ao atravessar um corpo; c) propagam-se em linha reta e em todas as direções; d) sua capacidade de atravessar um corpo é diretamente proporcional à tensão $(\mathrm{kV})$ dada ao tubo; e) obedecem à lei do inverso do quadrado da distância $\left(1 / \mathrm{r}^{2}\right)$; f) podem provocar mutações genéticas ao interagir com células reprodutivas ${ }^{6}$.

$\mathrm{O}$ feixe de raios $\mathrm{X}$, ao incidir no corpo do paciente, tem uma parte da sua radiação absorvida, uma parte que o ultrapassa e atinge o intensificador de imagem e outra parte que produz radiação secundária ou espalhada, a qual se dispersa para os lados e mesmo para trás. Os níveis de radiação espalhada dependem da espessura ou peso do paciente, da quilovoltagem e miliamperagem, da abertura dos colimadores, da distância tubo-intensificador e da projeção angiográfica. As projeções nas quais o tubo de raios $\mathrm{X}$ está no mesmo lado do operador são as que mais originam radiação secundária ${ }^{2}$.

\section{Efeitos biológicos da radiação}

Já é de conhecimento público os riscos da utilização inadequada de radiação ionizante, e partindo desses princípios a CNEN regulamentou sua utilização pela norma CNEN-NN-3.01. Por falta de treinamento de pessoal, a maior parte das unidades de radiologia ainda não tem uma adequada normatização de segurança para as atividades afins. Devido a essas situações, os maiores prejudicados são os profissionais envolvidos nos procedimentos radiológicos e a população consumidora de tais serviços, pois, devido à inadequação das técnicas, acessórios, material de consumo e equipamentos de proteção individual, todos ficam expostos ou se submetem a altas doses de radiação ionizante quando são executados os exames ou procedimentos radiológicos ${ }^{6,20,33}$.

Os mecanismos pelos quais a radiação ionizante age sobre a célula viva são vários e, em parte, desconhecidos. No processo de interação da radiação com a matéria, pode ocorrer ionização e excitação dos átomos e moléculas, provocando modificação na estrutura das moléculas. A lesão mais importante é a que ocorre no ácido desoxirribonucléico (DNA). Os efeitos agudos possivelmente se devem à ionização da água, que se decompõe e forma radicais livres, os quais influenciam no metabolismo celular, gerando substâncias oxidadas e o óxido de hidrogênio. Essa oxidação afeta grupos protéicos enzimáticos, especialmente o grupo sulfidril. Uma simples excitação eletrônica é capaz de romper 20 ligações de hidrogênio. Mesmo com doses pequenas de irradiação, os efeitos quantitativos podem ser maiores e com múltiplos rompimentos das cadeias protéicas. Além disso, pode ocorrer uma completa desintegração celular, embora haja a possibilidade de sua auto-restituição ${ }^{1,6,33,34}$.

Os efeitos induzidos pela radiação podem receber denominações em função do valor da dose, da forma de resposta do organismo e também em função do tempo de manifestação e da gravidade do efeito no organismo. A principal conseqüência da interação radiação/matéria é a excitação atômico-molecular, e os seus efeitos biológicos são classificados em: a) efeitos estocásticos, que causam uma alteração aleatória no DNA de uma única célula, que continua a reproduzir-se, e são proporcionais à dose de radiação recebida, sem existência de limiar de dose seguro (exemplos são os cânceres e a leucemia); b) efeitos determinísticos, que são alterações somáticas devido à morte celular e aparecem, em geral, dias ou semanas após a irradiação do órgão ou tecido e somente se o organismo tiver absorvido uma dose mínima de radiação, que é específica para cada órgão (exemplos são a leucopenia, náuseas, anemia, esterilidade, radiodermite e catarata) ${ }^{1,2,6,7,11,20,32,34}$. Os efeitos determinísticos de maior freqüência são: radiodermite crônica, alterações de contagem de glóbulos brancos e vermelhos, vasculites e alterações no sistema reprodutor. A leucemia, por ser a principal doença que ocorre devido à 
exposição crônica da radiação, torna obrigatória a realização de exame de sangue periódico como um dos controles médicos ocupacionais ${ }^{1,2,34}$.

As radiações ionizantes podem produzir mutações gênicas e cromossômicas e a relação entre dose e efeito é linear para estas mutações, não parecendo haver um limite abaixo do qual uma dose de radiação se mostre ineficaz em sua ação. Se uma mutação ocorre num gameta, poderá transmitir-se, logicamente, uma única vez. Caso se dê, porém, numa espermatogônia (mesmo de uma criança), poderá manter-se em tais células durante toda a vida do indivíduo, continuamente, passando aos gametas. As radiações podem, portanto, mostrar-se nocivas como agentes mutagênicos não só quando atingem adultos em franco período de reprodução, mas também quando administradas a crianças ${ }^{1,20,33-35}$.

Mesmo quando os níveis de exposição aos raios X forem baixos, é importante enfatizar que a exposição crônica pode levar a doenças malignas e também à catarata. Para os diferentes tipos de doença maligna que a radiação pode acarretar, os riscos seguem padrões de tempo diferentes, sendo que a leucemia parece ter um risco relativo constante no tempo, principalmente se o profissional está constantemente exposto à fluoroscopia. Para os tumores sólidos, como os cânceres de pulmão, mama, tireóide, estômago e cólon, o risco relativo diminui após cerca de 10 a 20 anos de exposição. A leucemia é o tipo de neoplasia secundária à exposição radiológica mais comum, seguida pelos tumores gastrintestinais, mama, pulmão e tireóide ${ }^{35}$.

O corpo humano tem plasticidade suficiente para reverter esses efeitos e muitas vezes reparar as células que ainda não sofreram lesões irreversíveis a ponto de inibir sua proliferação, porém as células germinativas danificadas podem ser lesadas irreversivelmente, e as alterações podem ser transmitidas para o feto ${ }^{1,6}$.

Azevedo ${ }^{6}$ adverte que os efeitos da exposição radiológica pré-natal dependem do período de gestação, e podem ocorrer falhas na fixação do embrião, com abortamentos e má formação de órgãos, aumento da probabilidade de câncer no recém-nascido e redução do quociente de inteligência (QI).
A legislação trabalhista assegura, por meio das NR 7 e 9, a prevenção e proteção dos profissionais empregados pelas instituições de saúde dos efeitos causados pela exposição à radiação ionizante, estabelecendo a obrigatoriedade do Programa de Controle Médico de Saúde Ocupacional (PCMSO) em associação com o Programa de Prevenção de Riscos Ambientais (PPRA). O PCMSO deve incluir obrigatoriamente a realização de exame médico admissional e periódico para os profissionais expostos à radiação, assim como o exame de laboratório mínimo, como o hemograma completo e a contagem de plaquetas semestralmente ${ }^{30,36}$.

\section{Conclusão}

Mesmo com todos os benefícios na área médica, as técnicas de radiodiagnóstico podem implicar risco à saúde, pois a obtenção de imagens para se conseguir o diagnóstico ou realizar uma terapêutica envolve o uso de raios $\mathrm{X}$ e, dessa forma, pode trazer prejuízos à saúde dos médicos e à equipe de saúde na sala de hemodinâmica.

Devido aos riscos inerentes no uso da radiação, houve necessidade da regulamentação de sua utilização. Assim, o MS, a CNEN e o MTE estabeleceram portarias e normas que seguem as diretrizes estabelecidas pela ICRP, determinando a implantação de um departamento radiológico de alta qualidade, com um eficiente programa básico de garantia de controle de qualidade de serviços, imagens e doses de radiação em profissionais e pacientes.

Dessa forma, é muito importante o desenvolvimento e a implantação de um sistema de segurança e proteção radiológica para ser aplicado no setor de radiodiagnóstico. Esse sistema deve abranger o controle das fontes de radiação e do pessoal que manipula tais fontes com um programa regular de treinamento dos profissionais envolvidos.

Portanto, é importante que as equipes médicas que trabalham em serviços de hemodinâmica tenham as condições adequadas para o desempenho de suas funções, com o mínimo de exposição e com um serviço de radioproteção que siga as normas estabelecidas internacionalmente. 


\section{Referências}

1. Cotran RS, Kumar V, Robbins SL. Patologia estrutural e funcional. In: Patologia ambiental: lesão por irradiação. $4^{\mathrm{a}} \mathrm{ed}$. Rio de Janeiro: Guanabara Koogan; 1991. p.387-434.

2. Soares JC. Princípios básicos de física em radiodiagnóstico. São Paulo: Colégio Brasileiro de Radiologia; 2002.

3. Associação Brasileira de Física Médica. Atribuições do especialista em radiodiagnóstico [site na internet]. Disponível em: http://www.abfm.org.br/exame_radiodiagnostico.asp. Acessado: 29/04/2005.

4. Medeiros RB. Proteção radiológica em procedimentos com fluoroscopia. Disponível em: http:// protecaoradiologica.unifesp.br. Acessado: 03/06/2005.

5. Oliveira SR, Azevedo ACP, Carvalho ACP. Elaboração de um programa de monitoração ocupacional em radiologia para o Hospital Universitário Clementino Fraga Filho. Radiol Bras. 2003;36:27-34.

6. Azevedo ACP. Radioproteção em serviços de saúde. Disponível em: http://www.biossegurancahospitalar.com.br/files/ raiox.doc. Acessado: 26/06/2005.

7. Kaude J, Svahn G. Absorbed, gonad and integral doses to the patient and personnel from angiographic procedures. Acta Radiol Diagn (Stockh). 1974;15:454-64.

8. Wholey MH. Clinical dosimetry during the angiographic examination: comments on coronary arteriography. Circulation. 1974;50:627-31.

9. Santen CB, Kan K, Velthuyse HJ, Julius HW. Exposure of the radiologist to scattered radiation during angiography. Radiology. 1975;115:447-50.

10. Gustafsson M, Lunderquist A. Personnel exposure to radiation at some angiographic procedures. Radiology. 1981;140:807-11.

11. Mostafa G, Sing RF, McKeown R, Huynh TT, Heniford BT. The hazard of scattered radiation in a trauma intensive care unit. Crit Care Med. 2002;30:574-6.

12. Universidade Federal do Rio Grande do Sul (UFRGS). Serviço de Proteção Radiológica. Disponível em: http:// www6.ufrgs.br/spr/apres.php. Acessado: 29/04/2005.

13. Cunha PG, Freire B, Drexler G. Occupational exposure in $X$ Ray diagnosis in Brazil. Radiat Prot Dosimetry. 1992;43:55-8.

14. Medeiros RF. Padronização da técnica de cateterismo cardíaco visando à proteção radiológica. In: International Radiation Protection Association (IRPA), Sociedade Brasileira de Proteção Radiológica (SBPR). $5^{\circ}$ Congresso Mundial de Proteção Radiológica; 2001; Recife. Disponível em: http:// www.rogeriofisicamedica.ubbi.com.br/. Acessado: 03/06/2005.

15. Brasil, Ministério da Saúde. Portaria 453, 1 jun. 1998. Diretrizes de proteção radiológica em radiodiagnóstico médico e odontológico. Brasília: Diário Oficial da República Federativa do Brasil, Poder Executivo, 02 jun. 1998, seção 1, p. 29. Disponível em: http://www.prorad.com.br/Pro/ portaria453.PDF

16. Ishiguro H. Concept and application of optimization for radiological protection. In: 10th International Congress of the International Radiation Protection Association; May 2000; Hiroshima, Japan. Disponível em: http://www.irpa.net/edu/ index.html?page.html $\% 3$ Ftopic.html $\% 24$ Documents $\% 7$ Eftopic _edu fpage_edu. Acessado: 13/05/2005.
17. Brasil, Ministério do Trabalho e Emprego. Portaria 485, 11 nov. 2005. NR 32: Segurança e saúde no trabalho em serviços de saúde. Diário Oficial da República Federativa do Brasil, Poder Executivo, Brasília, DF, 16 nov. 2005, seção 1, p. 80.

18. Gronchi CC. Exposição ocupacional às radiações ionizantes nos serviços de hemodinâmica [Dissertação]. São Paulo: Universidade de São Paulo; 2004.

19. Dietze G, Menzel HG. Aspects of ICRP 60 and ICRU 47 relevant to individual monitoring of external exposure. Radiat Prot Dosimetry. 1994;54:167-73.

20. Brasil, Ministério da Ciência e Tecnologia. Resolução 27, 6 jan. 2005. Diretrizes básicas de proteção radiológica. Norma CNEN-NN-3.01. Disponível em: http://www.cnen.gov.br/ seguranca/normas/mostra-norma.asp?op $=301$

21. Wyart P, Dumant D, Gourdier M, Nassar F, Bouthillon JC, Chestier Y. [Contribution of self-surveillance of the personnel by electronic radiation dosimeters in invasive cardiology]. Arch Mal Coeur Vaiss. 1997;90:233-8.

22. Brasil, Ministério do Trabalho e Emprego. Portaria 518, 7 abr. 2003. Atividades e operações perigosas com radiações ionizantes ou substâncias radioativas: atividades/áreas de risco. Diário Oficial da República Federativa do Brasil, Poder Executivo, Brasília, DF, 07 abr. 2003, seção 1, p. 104.

23. Araújo GM. Normas regulamentadoras comentadas. Legislação de segurança e saúde no trabalho. In: NR 16: atividades e operações perigosas. Anexo: atividades e operações perigosas com radiações ionizantes e substâncias radioativas. $5^{\mathrm{a}}$ ed. Rio de Janeiro: Virtual; 2005. v. 1, parte 2, anexo, p. 806-11.

24. Brasil, Ministério do Trabalho e Emprego. Trabalhador. CLT - Consolidação das Leis Trabalhistas. Título II: Das normas gerais de tutela do trabalho. Disponível em: http:// www.mte.gov.br/Trabalhador/CLT/default.asp. Acessado: 07/10/2005.

25. Pitt E, Schalch D, Scharmann A. Results of a comparative study on different personnel dosemeters. Radiat Prot Dosimetry. 1986;17:57-61.

26. Ban N, Nakaoka H, Haruta R, et al. Development of a real-time hand dose monitor for personnel in interventional radiology. Radiat Prot Dosimetry. 2001;93:325-9.

27. PRORAD - Consultores em Radioproteção Ltda. Manual do usuário. Disponível em: http://www.prorad.com.br/Pro/ manual\%20dosim.PDF. Acessado: 31/07/2005.

28. Medeiros RF. Monitoração pessoal em hemodinâmica. In: Universidade Federal do Rio Grande do Sul (UFRGS). $2^{\text {a }}$ Semana Científica do Hospital de Clínicas de Porto Alegre; 2000; Porto Alegre, RS. Disponível em: http:// www.rogeriofisicamedica.ubbi.com.br/. Acessado: 03/06/2005.

29. Araújo GM. Normas regulamentadoras comentadas. Legislação de segurança e saúde no trabalho. In: NR 06: equipamentos de proteção individual - EPI. $5^{\text {a }}$ ed. Rio de Janeiro: Virtual; 2005. v. 1, parte 2, p. 259-90.

30. Araújo GM. Normas regulamentadoras comentadas. Legislação de segurança e saúde no trabalho. In: NR 09: programa de prevenção de riscos ambientais. $5^{\mathrm{a}}$ ed. Rio de Janeiro: Virtual; 2005. v. 1, parte 2, p. 335-58. 
31. Balter S. Radiation safety in the cardiac catheterization laboratory: operational radiation safety. Catheter Cardiovasc Interv. 1999;47:347-53.

32. Araújo GM. Normas regulamentadoras comentadas. Legislação de segurança e saúde no trabalho. In: NR 15: atividades e operações insalubres. $5^{\text {a }}$ ed. Rio de Janeiro: Virtual; 2005. v. 1, parte 2, anexo 5, p. 565-77.

33. Rezende AF. Projeto de departamento radiológico padrão e garantia de controle de qualidade de serviços, imagens e doses de radiação em radiologia diagnóstica. Boa Vista: Unidade Radiológica do Posto de Saúde Pintolândia. Disponível em: http://www.nuclear.radiologia.nom.br/diversos/pcqptrr.htm. Acessado: 29/04/2005.

34. Boreham DR. Cellular defense mechanisms against the biological effects of ionizing radiation. In: 10th International Congress of International Radiation Protection Association (IRPA); May 2000; Hiroshima, Japan. Disponível em: http:// w3.tue.nl/fileadmin/sbd/Documenten/IRPA_refresher_ courses/Cellular_Defense_Mechanisms_Against_the_ Biological_Effects_of_Ionizing_Radiation.pdf. Acessado: $13 / 05 / 2005$.
35. Cohen RV, Aldred MA, Paes WS, et al. How safe is ERCP to the endoscopist? Surg Endosc. 1997;11:615-7.

36. Araújo GM. Normas regulamentadoras comentadas. Legislação de segurança e saúde no trabalho. In: NR 07: programa de controle médico de saúde ocupacional. $5^{\mathrm{a}} \mathrm{ed}$. Rio de Janeiro: Virtual; 2005. v. 1, parte 2, p. 291-330. Disponível em: http://www.mte.gov.br/Trabalhador/CLT/default.asp. Acessado: 07/10/2005.

Correspondência:

Edvaldo de Souza

Rua Mirassol, 315, Vila Clementino

CEP 04020.060 - São Paulo, SP

Tel.: (11) 9860.3906

E-mail: edvaldo@sbacvsp.org.br

\section{Submissão de figuras ao J Vasc Bras}

\section{Prezados Autores:}

Estamos numa campanha para melhorar a qualidade das imagens publicadas no Jornal Vascular Brasileiro.

Contribua você também: leia as normas e certifique-se de enviar figuras que atendam aos requisitos técnicos e de qualidade.

Figuras devem ser enviadas em formato eletrônico (exclusivamente gráficos e fotografias digitais), em arquivos independentes, nas extensões .jpg, .gif ou .tif, com resolução mínima de 300 dpi. Quando não for possível enviar as figuras por e-mail, o envio deve ser feito via correio. 